\title{
Can an emergency department clinical "triggers" program based on abnormal vital signs improve patient outcomes? - CORRIGENDUM
}

Jason Imperato; Tyler Mehegan; Daniel J. Henning; John Patrick; Chase Bushey; Gary Setnik; Leon D. Sanchez

doi: $10.1017 /$ cem.2016.365

In the original publication of "Can an emergency department clinical 'triggers' program based on abnormal vital signs improve patient outcomes?," there was an additional author left out: Daniel J. Henning, MD, MPH, affiliated with the Division of Emergency Medicine at University of Washington, Seattle, WA. Henning should have been listed third in author order.

The authors and editors regret this omission, and the author has been added into the original publication.

\section{REFERENCE}

Imperato J, Mehegan T, Henning DJ, Patrick J, Bushey C, Setnik G, Sanchez LD. "Can an emergency department clinical 'triggers' program based on abnormal vital signs improve patient outcomes?". CFEM 2016;18(6):495 doi:10.1017/cem.2016.365. 